\title{
Prototipo: Sistema de geolocalización para vehículos de carga mediante Smartphone
}

\section{Prototype: Geolocation system for cargo vehicles using Smartphone}

\author{
MENDOZA-ZUÑIGA, Armando $\dagger^{*}$, ARCADIO-DIONICIO, Pedro, MORALES-BENÍTEZ Ma. Isabel \\ y PEREZ-VAZQUEZ, Jenner
}

Universidad Tecnológica del Sur del Estado de México

ID $1^{\mathrm{er}}$ Autor: Armando, Mendoza-Zuñiga / ORC ID: 0000-0002-5091-6135, CVU CONACYT ID: 548045

ID $1^{\text {er }}$ Coautor: Pedro, Arcadio-Dionicio

ID $2^{\text {do }}$ Coautor: Ma. Isabel, Morales-Benítez

ID $3{ }^{\text {er }}$ Coautor: Jenner, Perez-Vazquez / ORC ID: 0000-0003-2475-6745, CVU CONACYT ID: 999003

DOI: $10.35429 / \mathrm{JCS} .2019 .9 .3 .17 .21$

Recibido: 12 de Junio, 2019; Aceptado 30 de Septiembre, 2019

\begin{abstract}
Resumen
Este proyecto propone una alternativa de localización de vehículos de transporte de mercancías. Se propone utilizar una técnica que consiste en la reutilización de la tecnología GPS integrada en un dispositivo móvil, el cual tendrá la ventaja de utilizar los teléfonos con sistema operativo Android - el más común en el mercado con precios al alcance de los diferentes segmentos de clientes. Ayudar a reducir perdidas en distintas PYMES es uno de los objetivos del proyecto, así como también ahorrar en gastos, para mejorar el nivel de status que tiene cada una de las empresas frente al mercado comercial. A partir de esto, se pretende que el servicio a desarrollar se adapte a los distintos contextos empresariales, para cumplir con la resolución de los problemas de extravíos de vehículos con mercancías encontrados en el mercado potencial. Con respecto al desarrollo del sistema, se decidió que será utilizada tecnología Open Source, mejor conocida como lenguajes de código abierto, lo cual hará que reduzca el costo del servicio. Este proyecto aplica investigación aplicada y se desarrollara mediante la metodología de cascada.
\end{abstract}

Desarrollo de Aplicaciones WEB, Desarrollo de App móvil, Geolocalización, GPS

\begin{abstract}
This project proposes an alternative location for freight vehicles. It is proposed to use a technique that consists of the reuse of GPS technology integrated in a mobile device, which will have the advantage of using phones with Android operating system - the most common in the market - with prices within reach of the different segments of customers. Helping to reduce losses in different PYMES is one of the objectives of the project, as well as saving on expenses, to improve the level of status that each of the companies has in relation to the commercial market. From this, it is intended that the service to be developed adapts to the different business contexts, to comply with the resolution of the problems of lost vehicles with merchandise found in the potential market. Regarding the development of the system, it was decided that Open Source technology, better known as open source languages, will be used, which will reduce the cost of the service. This project applies applied research and will be developed using the waterfall methodology.
\end{abstract}

WEB Application Development, Mobile App Development, Geolocation, GPS

\footnotetext{
* Correspondencia al Autor: (amz2010_4@ hotmail.com)

$\dagger$ Investigador contribuyendo como primer autor.
} 


\section{Introducción}

Este proyecto se emprende con docentes y alumnos de la Universidad Tecnológica del Sur del Estado de México y tiene como tópicos a investigar: el estudio del contexto de los sistemas de geo localización implementados en la zona de influencia (Tejupilco, Estado de México), Geolocalización, Desarrollo de Apps y Desarrollo web, que conjuntamente establecerá un prototipo funcional para las pequeñas empresas de mercancías (PYMES), de esta manera tendrán el seguimiento y monitoreo del trayecto de sus mercancías; asi mismo la importancia de la utilidad del GPS inmerso en los SmartPhone que no les genera costo alguno de un dispositivo GPS.

Para ello la tecnología GPS (Sistema de Posicionamiento Global), la cual utiliza fue desarrollada por el departamento militar para el posicionamiento y navegación en EEUU. El sistema cuanta con 30 satélites en órbita con una distancia de 20 mil kilómetros. Se determinó, que existen al menos cuatro satélites de GPS que están visibles en cualquier momento. Cada uno de ellos trasmite una señal sobre su ubicación, dichas señales viajan a la velocidad de la luz y son interceptadas por el receptor de GPS, en este caso el celular smartphone.

El receptor calcula a qué distancia está de cada satélite según el tiempo que le tomó recibir el mensaje, para así obtener la señal de al menos tres satélites y poder triangularlas. Y gracias a ello poder obtener la ubicación (Abc Tecnología, 2014). Anteriormente se mencionó, la existencia de sistemas que se dedican a la localización de vehículos, de los cuales se han tomado como referencia algunas de las formas de funcionamiento, para ello se encontraron las siguientes patentes, sin embargo, ninguna de ellas realiza las mismas funciones que se pretenden implementar: (México Patente No. 342096, 2014). Sistema de geolocalización, telemetría, comunicación, monitoreo y seguridad de vehículo, (US Patente No. 320759 , 2012). Sistema y método para el rastreo de vehículos, (US Patente No 310320, 2008). Métodos y sistemas de procesamiento y transmisión de información para transportistas de mercancías, (US Patente No 275086, 2004). Sistema de ubicación y recuperación de vehículos, (EU Patente No PCT/US2010/001117,2012). Sistema de identificación y monitoreo de vehículo, entre otras.

\section{Justificación}

En la actualidad, existe una alta incidencia en el robo al transporte de carga. De acuerdo con Córdova (2017) en el año 2016 se reportaron 4,550 unidades de transporte de carga perdidas, de las cuales 2,050 son camiones y 2,500 tractocamiones, para lo cual, se estimó que en el primer semestre del presente año hubo pérdidas por más de 600 millones de pesos por robo al transporte. Esto implica pérdidas económicas importantes para las empresas y aún más para una microempresa. El periódico El UNIVERSAL en el Estado de México (2011) presentó las modalidades utilizan los ladrones para robar los vehículos a sus dueños:

Abandonan el auto. Gracias a la gran afluencia que han tenido las personas para cuidar sus vehículos de los robos realizan gastos adiciónales para ellos. Una vez que los ladrones hurtan un auto, lo abandonan en colonias donde se pueda confundir con los demás, en un lapso corto de dos a tres días para verificar que el vehículo no cuente con ningún dispositivo de rastreo. Esto principal- mente lo hacen para automóviles recientes.

Simular un choque. Para realizar este tipo de robo lo primero que hacen los ladrones es fingir un choque, posteriormente se bajan de su auto y distraen al dueño del auto a robar el cual sale y deja las llaves, mientras los ladrones que simularon el choque salen huyendo, y los que distraían al dueño suben al auto que desean robar supuestamente a seguirlo, pero es de lo contrario se roban el auto junto con sus cómplices.

Para atender la problemática antes mencionada, existen diversas alternativas de localización y recuperación. Por ejemplo, en la actualidad se pueden encontrar en el mercado sistemas como: Startraq cuya funcionalidad es enviar notificaciones si un vehículo sale o entra de un área predefinida. También existe Lo Jack, un sistema basado en radio frecuencia que permite localizar vehículos robados aún en lugares techados y subterráneos. Existe el "Avisor-Centinela" de la Dirección General de Seguridad Pública (DGSP) de la Comisión Nacional de Seguridad (CNS) de la Secretaría de Gobernación (SEGOB). 
También, el GPS Asintec un sistema de geolocalización de vehículos mediante un dispositivo localizador extra en el automóvil en interacción con el satélite mediante un GPS para obtener los puntos de ubicación teniendo la opción de guardar la información en un dispositivo de memoria para analizar los datos o realizar la geolocalización en tiempo real (GPS Asintec, 2012).

Los sistemas mencionados anteriormente, tienen la característica de que necesitan de un dispositivo GPS adicional para montarlo en el automóvil, además es necesario obtener una tarjeta SIM para ese dispositivo, lo cual genera un gasto adicional para las empresas (clientes) y estos sistemas están asociados a la compra de un seguro o a disposición de las empresas que se encuentran en las grandes ciudades. Por tanto, lo que se busca con este proyecto, son alternativas de bajo costo y que sean efectivas para resolver la problemática antes presentada.

Para ello, este proyecto propone una alternativa de localización de vehículos de transporte de mercancías que contribuya a la reducción de gastos. Para ello, se llevará a cabo, una técnica poco común, que es la reutilización de la tecnología GPS integrada en un dispositivo móvil o Smartphone, como medio para la geolocalización de unidades de transporte robadas. Este medio tendrá la ventaja de utilizar los teléfonos con sistema operativo Android - el más común en el mercado - con precios al alcance de los diferentes segmentos de clientes.

\section{Descripción del Proyecto}

El presente proyecto trata de un producto servicio el cual se encargará de monitorear el recorrido del automóvil de carga para las empresas que cuenten con dicho servicio. La localización del vehículo será mediante la tecnología GPS inmerso en un celular. Se considera que la interfaz es amigable porque no habrá redundancia en las vistas; los iconos serán adaptados acorde su función. La persona que trasporta el auto será quien llevará el dispositivo que permitirá al sistema poder monitorear el recorrido del automóvil hasta su destino final. La interfaz del sistema será amigable con los usuarios ya que no contiene información ambigua y es de fácil interacción.
Para localizar un vehículo es necesario contar con el dispositivo con GPS, en este caso al brindar el servicio se estará utilizando un Smartphone el cual goza de un sistema operativo Android, con el que cuentan la mayoría de las personas por su fácil accesibilidad en precio. $\mathrm{La}$ geolocalización de un automóvil de carga será monitoreada por una aplicación web, que tendrá la función de observar la trayectoria de cada uno de los dispositivos conectados a esa red; para ello accederá a la aplicación móvil que estará instalada en el dispositivo.

El sistema de geolocalización de mercancías tendrá como función monitorear la ubicación de los vehículos de trasporte, con la ayuda del Smartphone, así el chofer de la unidad llevará un Smartphone el cual será rastreado mediante el GPS, sin necesidad de obtener otro aparato de rastreo. Tanto la aplicación web y móvil serán manejables para los usuarios, pues no se requiere un nivel de complejidad alto para poder manejar el dispositivo de manera correcta.

La aplicación móvil es la encargada de enviar los datos de ubicación obtenida del GPS, al servidor web con ayuda de los datos móviles, en caso de estar fuera del área de cobertura los datos serán almacenados en un archivo de texto $\mathrm{y}$ enviados posteriormente al servidor web cuando se recupere la señal telefónica o mediante $\mathrm{WiFi}$, entonces la aplicación web leerá los datos obtenidos y mostrara en el mapa la posición actual del vehículo (Figura 1).

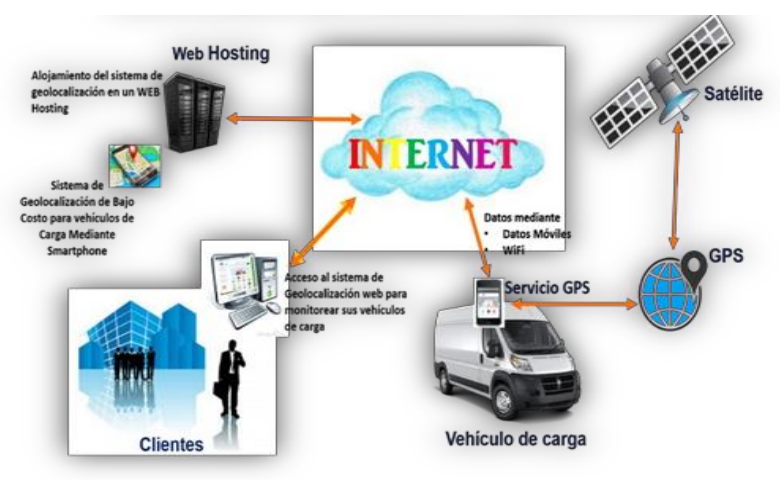

Figura 1 Prototipo conceptual del sistema de geolocalización para vehículos de carga mediante Smartphone

Las pequeñas y medianas empresas que se encargan de repartir sus mercancías, no tienen la suficiente facilidad para invertir en dispositivos de localización para sus autos de transporte, esto les implica pérdidas, tanto en vehículos como mercancías ya que en muchos de los casos son robadas. 
Algunas empresas, su labor primordial es la entrega de mercancías a distintos comercios, por lo que la pérdida de ellas incluye baja económica. Es por ello, que es necesario que exista un servicio de geolocalización de sus vehículos pero que sea de bajo costo para mejorar el transporte de cada una esas mercancías con mayor seguridad.

La principal ventaja de este proyecto es la reutilización de la tecnología GPS inmersa en los celulares con sistema operativo Android, en caso de no contar con servicio de red telefónica, los datos que envía el GPS al servidor web serán almacenados en un archivo de texto, una vez obtenida la red telefónica el archivo de texto será enviado al servidor. El proyecto, ayudará a las empresas de transporte de mercancías a bajar el impresionante aumento de robo de vehículos de carga que ha crecido más del $50 \%$ en el territorio nacional, del cual no han disminuido estas cifras (De la Rosa, 2017), al reducir el robo de estas mercancías con ayuda del sistema, las empresas podrán aumentar los servicios en otros mercados sin miedo de tantas perdidas. En caso de que un automóvil sea hurtado e sistema web se percatara que has salido de la ruta de transporte y podrán llevar a cabo las medidas de recuperación del vehículo.

La figura 2 presenta los componentes y funcionamiento general del sistema con las siguientes características:

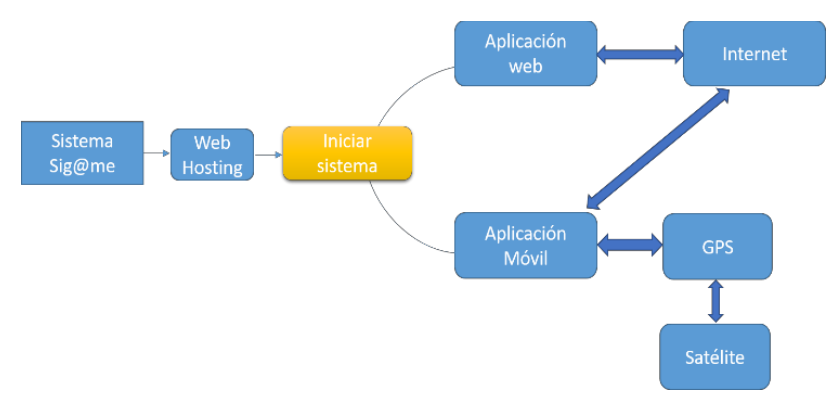

Figura 2 Funcionamiento general del Proyecto

Cada uno de los componentes para el funcionamiento del sistema se describe a continuación:

Sistema de Geolocalización del Proyecto: Representa el nombre del sistema que incluye las aplicaciones web y móvil donde la web es alojada en el Web Hosting.
Web Hosting: Es el espacio para el alojamiento del sitio web en un servidor en Internet, de esta manera tendremos alojado el sitio para realizar consultas de cada empresa las 24 horas del día, los 365 días del año.

Iniciar sistema: Esta representa la acción de ejecutar la aplicación ya sea web o móvil dependiendo del tipo de usuario o cliente que requiera el uso de estas aplicaciones, tomando en cuenta de que si se inicia la aplicación web se está consultando por vía remota desde Internet.

Aplicación web: Es la aplicación se puede consultar teniendo acceso a Internet ya que será la aplicación (servidor) que recibirá los datos enviados por el teléfono celular para visualizar el punto de ubicación del vehículo.

Aplicación móvil: Es la aplicación cliente que envía los datos de latitud y longitud hacia el satélite mediante el GPS, el satélite retorna las coordenadas geográficas de tal manera que el dispositivo envía estos datos al servidor web con el acceso a Internet, la comunicación que enlaza a estas dos aplicaciones es el Internet.

GPS: El GPS es el medio de transmisión para el envío de datos (longitud y latitud) hacia el satélite para que este retorne las coordenadas que proporcionan el punto de ubicación.

Satélite: Es la nave espacial que recibe los datos de latitud y longitud para calcular el punto de ubicación del vehículo mediante coordenadas geográficas de la tierra.

La Funcionalidad del Sistema (Figura 3) empieza mediante la aplicación instalada en el Smartphone, en la cual, el conductor del automóvil de carga indica la hora de salida, llegada y entrega de mercancías pulsando un botón de la aplicación móvil para que el servidor web lleve el monitoreo del vehículo y reciba los datos enviados por el Smartphone para poder comprobar los datos correspondientes, de tal manera que el monitoreo se lleve en tiempo real.

Para esto, el servidor se mantendrá informado con respecto a los conductores, números telefónicos de los Smartphone, datos de las entregas, así como datos de los lugares de destino de las mercancías guardados en una base de datos. 
También en la aplicación móvil se llevará el registro de datos de forma temporal en un archivo de texto, para posteriormente guardarlos en la base de datos del servidor. La transmisión de información será por medio del GPS del Smartphone en comunicación con el satélite y después con el servidor web a través de internet.

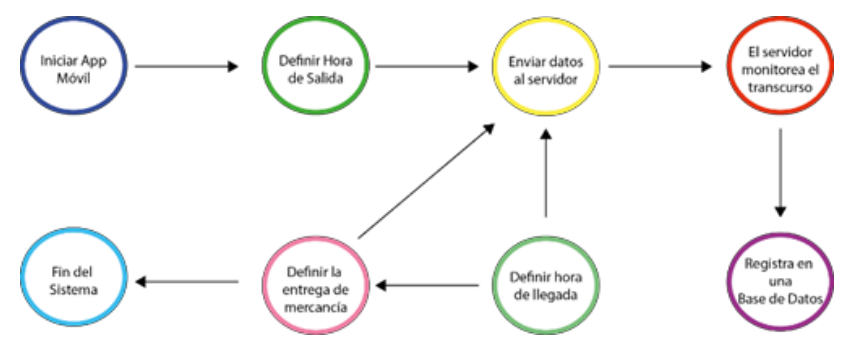

Figura 3 Operación del uso del proyecto, así como la forma de envió de datos

Así, el proyecto consta de dos aplicaciones las cuáles son: i) aplicación web; y ii) la aplicación móvil

\section{Conclusiones}

En conclusión, se logró realizar el prototipo mediante las necesidades que el sector empresarial demandaba, y establecer las funciones esenciales de monitorear las rutas de trasporte de mercancías de las empresas. Al igual los objetivos planteados, fueron exitosos ya que se cumplió con cada uno de ellos, dándonos como resultado la construcción del modelo del sistema. Sin embargo, esto no hubiera sido posible sin el plan de trabajo propuesto inicialmente, tales como el análisis de todos los conceptos necesarios para el desarrollo del prototipo del sistema, al igual que el diseño del prototipo conceptual, de funcionamiento y de esquema funcional del Proyecto. Cabe mencionar que dicho proyecto no ha sido finalizado totalmente el prototipo.

Mis recomendaciones para el proyecto es diseñar e implementarlo con tecnologías Open Source, y aumentar la funcionalidad del prototipo del sistema que además de localización de vehículos también tenga la administración de sus mercancías para que fuera aún más servicial para el mercado.

\section{Referencias}

Abc Tecnología. (20 de marzo de 2014). Geolocalización: ¿cómo es posible que el móvil sepa dónde estamos? Recuperado el 15 de junio de 2017, de Abc Tec- nología: http://www.abc.es/tecnologia/movilestelefonia/20140320/abci- localizacion-movil201403192024.html

Company, T. g. (12 de enero de 2012). US Patente $\mathrm{n}^{\circ} 320759$.

Córdova, Y. (30 de noviembre de 2016). Robo a transporte de carga creció 200\%. El Economista. Obtenido de http://eleconomista.com.mx/sociedad/2016/11/ 30/ robo-transporte-carga-crecio-200

Corporation, L. (02 de julio de 2004). US Patente $\mathrm{n}^{\mathrm{o}} 275086$.

EL UNIVERSAL edomex. (15 de enero de 2011). Las 5 formas más comunes del robo de autos. El Universal Estado de México. Obtenido de El Universal Estado de México: http://www.eluniversaledomex.mx/otros/nota1 1899.html

GPS Asintec. (2012). Localización de vehículos. Recuperado el 29 de Mayo de 2017, de GPS Asintec: http://www.asintecgps.com/localizacion-gps/ localizacion-de-vehiculos http://www.gps.gov/systems/gps/spanish.php inc., R. c. (23 de julio de 2008). US Patente $\mathrm{n}^{\circ}$ 310320 .

Zaragoza, A. D. (19 de marzo de 2014). México Patente $n^{\circ} 342096$.

Zlojutro, M. (15 de octubre de 2012). EU Patente ${ }^{\circ}$ PCT/US2010/001117. 